\title{
LA PERSUASIÓN COERCITIVA, MODELO EXPLICATIVO DEL MANTENIMIENTO DE LAS MUJERES EN UNA SITUACIÓN DE VIOLENCIA DE GÉNERO I: Las estrategias de la violencia
}

THE COERCIVE PERSUASION, AN EXPLANATORY MODEL OF THE STAY OF WOMEN IN A SITUATION OF GENDER-BASED VIOLENCE. I: VIOLENCE STRATEGIES.

\section{RESUMEN}

En este estudio investigamos las condiciones que influyen en la prolongación o permanencia de las mujeres víctimas de violencia de género en la relación con el maltratador. Se diseñó un estudio cualitativo basado en el análisis de grupos de discusión con mujeres víctimas de maltrato en la relación de pareja. Se utilizaron para el análisis los presupuestos de la Teoría Emergente (The Grounded Theory). De los distintos modelos principales propuestos en la literatura: aplicación del concepto de masoquismo en la mujer, la indefensión aprendida, variaciones del «síndrome de Estocolmo», el «ciclo de la violencia» o la persuasión coercitiva, sólo los dos últimos pudieron dar coherencia a los distintos temas que emergieron en los grupos del estudio. El modelo que desarrollamos establece que en la violencia de género se producen una serie definida de estrategias de persuasión coercitiva cuya finalidad es perpetuar el control del maltratador sobre la víctima. Estas estrategias generan un progresivo estado de confusión de emociones, distorsión de pensamientos y paralización que dificultan que la mujer abandone la relación establecida por el sujeto maltratador.

Palabras clave: violencia de género, persuasión coercitiva, lavado de cerebro, estrategias de violencia.

\section{ABSTRACT}

In this research we investigated the conditions that influence in the prolongation or permanence of the women who are victims of violence in the relation with the abuser. We designed a qualitative study based on the analysis of group discussions with these women. The «Grounded Theory» for the analysis of the data was used. Different models proposed in Literature are reviewed: application of the concept of masochism in the woman, the learned helplessness, «syndrome of Stockholm», the "cycle of the violence» or the coercive persuasion. Only both last models offered a coherent explanation to the set of the different subjects that emerged in the groups of the study. The model that we developed establishes that in the gender violence a defined series of strategies of coercive persuasion takes place. The purpose of these strategies is to perpetuate the control of the abuser. So the coercive persuasion generates a progressive state of emotional confusion, distortions of thoughts and paralysis that make difficult that the woman can leave the relation.

Key words: gender-based violence, coercive persuasion, brainwashing, violence strategies. 


\section{INTRODUCCIÓN}

Según Rhodes y Baranoff McKenzie (1), la pregunta ¿Por qué las mujeres permanecen en relaciones de maltrato?, constituye la cuestión más frecuente respecto a las mujeres que sufren violencia por sus parejas.

Desde la investigación clínica y social se han formulado diversos modelos explicativos. El que tuvo un origen más temprano, manteniéndose todavía vigente, buscó la causa en una condición masoquista de la mujer. La violencia ejercería el papel de un mediador en el equilibrio, tanto de la relación de pareja, como de las necesidades individuales de sus miembros. Según autores como Snell, Rosenwall, y Robey (2), los periodos de conducta violenta «liberaban» al hombre de su angustia por su inoperancia como tal, al tiempo que permitían a la mujer obtener una satisfacción masoquista; esta última «ayudaba» a la mujer a manejar «su culpa» derivada de su propia «hostilidad expresada en su conducta controladora y castradora». La explicación masoquista es formulada también a partir del concepto del «mecanismo de compulsión a la repetición» (3). Desde dicho presupuesto teórico, se formulan propuestas terapéuticas dirigidas a tratar en las mujeres estos supuestos mecanismos inconscientes. Otros autores psicoanalistas como Bleichmar (4) e Hirigoyen (5), han advertido sobre lo que puede ser un uso abusivo y mal comprendido del concepto.

El modelo de «indefensión aprendida» fue propuesto por Walker en 1979 (6) aplicando las investigaciones de Seligman (7). Según este modelo, una mujer sometida a acontecimientos incontrolables, en este caso actos violentos, generará un estado psicológico donde la respuesta de reacción o huida queda bloqueada. Propuesto como alternativa científica frente a la teoría del masoquismo femenino, fue no obstante posteriormente criticado desde el análisis feminista por el énfasis que ponía sobre una actitud pasiva en la mujer. Al igual que el modelo del masoquismo, sigue teniendo una presencia actual dentro de las teorías explicativas. Para La Violette y Barnett (8), la imposibilidad de controlar la agresión generará en la víctima una afectación motivacional y pasividad consiguiente, dificultades para la resolución de problemas, y por tanto la confrontación con la situación, al tiempo que un trauma emocional que se manifiesta en forma de indefensión, incompetencia, frustración y depresión.

Walker (6), conceptualizó también el «ciclo de la violencia» el cual ha alcanzado amplia difusión. Este modelo suelen comprender tres fases: La fase de acumulación o de generación de tensión; en ella la mujer actuaría con un comportamiento pasivo como medio de protección. La fase de agresión o descarga de la tensión, en la cual la mujer intenta calmar al agresor. $Y$ tras el ataque, la fase de arrepentimiento del maltratador que generará una ficción de reencuentro llamada «luna de miel», hasta el inicio del nuevo ciclo.

Los antecedentes de violencia sufrida en etapas tempranas de la biografía de la víctima han constituido un modelo explicativo basado en el aprendizaje de pautas de maltrato y victimización (9). 
La Teoría del aprendizaje social, hará hincapié en una transmisión de pautas agresivas a partir del mensaje, según el cual el ejercicio de la violencia comprende consecuencias positivas (o ventajosas) para el agresor. No obstante, según un meta-análisis realizado por la $0 \mathrm{NU}$, una familia de origen violento constituye sólo una variable más que hay que considerar en la etiología de la violencia contra la mujer (10).

De forma más reciente se están aplicando elementos del modelo de identificación con el agresor correspondientes al llamado Síndrome de Estocolmo. Autores como Graham y Rawlings (11) lo describen como un estado disociativo en la víctima por el que se niega la violencia del agresor, al tiempo que se desarrolla un vínculo con el lado que percibe más positivo de aquel. Para ello, la víctima ha de ignorar sus propias necesidades mientras desarrolla una actitud hipervigilante ante las de su agresor.

Graciela Ferreira (12) estableció una similitud con los prisioneros de guerra o las víctimas de los secuestros. El síndrome de Estocolmo se establecería a través de un estrés postraumático e integración del trauma.

En nuestro medio, Montero $(13,14)$ ha descrito el denominado Síndrome de Estocolmo Doméstico (SIES-d). Según el modelo, se constituye una fase adaptativacognitiva que culmina un proceso reactivo de una víctima aislada en un entorno traumático. El principal propósito de la fase podría ser obtener un mejor nivel de ajuste de la víctima al entorno amenazante sobre el que ejerce nulo control. A partir de aquí el síndrome es definido como un vínculo interpersonal de protección construido entre la víctima y el agresor, dentro de un ambiente aislado de estímulos, a través de la inducción de un modelo mental de naturaleza cognitiva dirigido a la recuperación del equilibrio fisiológico y conductual de la víctima y la protección de la integridad psicológica.

La persuasión coercitiva como modelo explicativo del mantenimiento de la mujer en una situación de maltrato tiene una representación dispar en la bibliografía revisada. Su mención o no, es pareja al concepto de «lavado de cerebro».

Miller (15) aplica a su desarrollo sobre los abusos psicológicos el concepto de «lavado de cerebro». El mismo se realizaría a través de: La cautividad (que establece como sinónimo de contexto de indefensión aprendida); el deterioro de la salud; el aislamiento; la propaganda (descalificaciones continuas); y la ansiedad (por medio de conductas cambiantes y de las amenazas). Miller hablará de los efectos de los «juegos mentales» como resultado de la pérdida de la identidad original de la víctima. Otros autores mencionarán el lavado de cerebro como un efecto de la cautividad, y causa, junto al síndrome de Estocolmo, de identificación con el agresor (8).

La aplicación más completa del concepto de «control mental» o «persuasión psicológica» a la violencia de género, lo hemos encontrado en un trabajo de Boulette y Andersen de 1985 (16). Estas autoras describen una serie de estrategias coercitivas aplicadas en sectas como «una variación en el fenómeno del maltrato el cual fue inicialmente observado entre mujeres de bajos ingresos económicos». 
No obstante, la persuasión coercitiva, según el análisis de distintos autores, es más amplio que el concepto de «lavado de cerebro». Así, Rodríguez Carballeira (17) en su amplia monografía los titula como sinónimos al tiempo que hace esta ampliación del concepto. En las próximas líneas hacemos una breve revisión de ambos conceptos.

El concepto de persuasión coercitiva se desarrolla a partir de las investigaciones psicosociales descritas por Schein, Scneider y Barker en 1961 (18, 19) sobre las transformaciones a las que fueron sometidos prisioneros de guerra norteamericanos tras ser capturados por los combatientes comunistas chinos en la Guerra de Corea. En una acepción amplia, la persuasión coercitiva se distingue de otras formas de influencia, en que en la primera la persona destinataria es física o psicológicamente sometida a continuas situaciones de presión para su «desocialización».

La representación de la reforma del pensamiento a través de términos como lavado de cerebro y persuasión coercitiva se encontraban ya en los manuales diagnósticos y estadísticos de los trastornos mentales (DSM), desde su versión DSM-II hasta el actual DSM-IV-TR (20). El lavado de cerebro, si bien marginalmente, se encuentra representado dentro de la categoría de Trastorno disociativo no especificado del DSM-IV (300.15) y del DSM-IV-TR, y a su vez dentro de éste, como una forma de persuasión coercitiva: «3. Estados disociativos que pueden presentarse en individuos que han estado sometidos a períodos de prolongada e intensa persuasión coercitiva (p. ej., lavados de cerebro, modificación del pensamiento o indoctrinamiento en sujetos cautivos)».

Loewenstein y Putnam (18) refieren que individuos sometidos a técnicas de extrema coerción tienen riesgos de sufrir una despersonalización persistente y posiblemente otros síntomas disociativos (amnesias, comportamientos similares al trance, y entumecimiento emocional). Pueden exhibir flexibilidad cognitiva reduci$\mathrm{da}$, regresiones conductuales y profundos cambios de valores, actitudes, creencias y sentido del sí-mismo.

Es difícil determinar un consenso para el propio concepto de persuasión coercitiva. Rodríguez Carballeira opta por la definición de J.W. Vander Zander (17) quien entiende la persuasión como «el ejercicio deliberado de una persona o grupo de influir en las actividades o conductas de otros, con el objeto de alcanzar algún fin preestablecido». Se sobrentiende por tanto que la persona persuadida, mientras actúa dicho proceso, es ajena a la modificación intencionada que se pretende ejercer sobre ella.

El segundo elemento: «coercitivo», que diferencia de otras persuasiones sin este adjetivo, implica: «el ejercicio de una presión intensa sobre el sujeto, limitando su libertad de elección, para dar así potencialmente más probabilidades a la obtención de la persuasión deseada». La coerción, en su doble acepción coerción/coacción es definida como «el uso de la fuerza para impedir u obligar a alguien a hacer algo». 
Para Rodríguez Carballeira, el uso más adecuado del concepto «fuerza» permite su comprensión bajo su sentido más amplio, en tanto que abarca sus diversas formas: física, psíquica o social, directa o indirecta, expresa o amenazante, etc.

Boulette y Andersen (16) describen varias «estrategias coercitivas» en la violencia contra la mujer:

Dominación desde las primeras fases de la relación por el hombre a través de actos psíquicos y físicos, malinterpretados por la mujer bajo la representación de «hombre con carácter». Aislamiento/aprisionamiento. Escalada en el miedo y mantenimiento de éste. Inducción de culpa. Expresión contingente de «amor». Lealtad al agresor y autodenuncia, lo cual las autoras lo asemejan al Síndrome de Estocolmo. Promoción del sentimiento de incapacidad e indefensión (relacionado con la indefensión aprendida de Seligman). Expresión patológica de celos. Reforzamientos intermitentes a través de comportamientos que generan esperanza. $Y$ exigencia de secreto.

De igual forma, el concepto de «lavado de cerebro» tiene un reconocimiento científico ambiguo.

Según Virginia A. Sadock (21): «El lavado de cerebro se apoya tanto en la coerción física como mental. Todas las personas son vulnerables al lavado de cerebro si son expuestas durante un tiempo suficiente, si están solas y sin apoyos, y si se encuentran sin esperanza de escapar de la situación».

El término fue acuñado en 1951 por Hunter, un periodista identificado más tarde como agente de la Central Intelligence Agency [CIA] $(18,19)$. Para Loewenstein y Putnam (18), «un legado del miedo la lavado de cerebro comunista fue el desafortunado mal uso de la psiquiatría y la psicología por la CIA y otras agencias gubernamentales de Estados Unidos desde finales de los cuarenta en adelante para desarrollar métodos de control de la conducta». Su uso en estos medios, en alegaciones de lavados de cerebro en el contexto de movimientos religiosos a finales de los años sesenta y setenta, o su discusión en famosos juicios con gran implicación mediática, determinaron que el término fuese evitado en medios académicos en la última década. Actualmente se encuentra, junto con el trastorno por trance disociativo (incluidos trastornos culturales como el amok, latah, etc), o el Síndrome de Ganser, dentro de los llamados «trastornos disociativos de otra manera no especificados (NOS)» incluidos en el DSM-IV-TR (20). Esto, más que dar cuenta de un fenómeno, lo elude al tiempo que lo contempla.

Esta devaluación académica del concepto de lavado de cerebro y su confusión como sinónimo del concepto de persuasión coercitiva, ha podido determinar que ambos términos -salvo en el trabajo citado de Boulette y Andersen (17)- no hayan sido estudiados en profundidad como un modelo explicativo del mantenimiento de la situación de maltrato. 


\section{PARTICIPANTES Y MÉTODO}

Nuestro estudio (22) se enfocó como una opción estratégica de investigación de las experiencias y los sistemas creenciales de las propias mujeres víctimas de situación de maltrato. Las mujeres participantes fueron seleccionadas según lo que en investigación cualitativa se denomina muestreo «teorético». Este constituye un tipo específico de muestreo no probabilístico en el cual el objetivo de la teoría en desarrollo guía el proceso de muestreo y colección de datos (23).

El propósito de dicho muestreo según Mays y Pope (24) es «identificar grupos específicos de personas quienes ya poseen esas características o viven en circunstancias relevantes para el fenómeno que está siendo estudiado».

\section{Generación de datos: Los grupos de discusión como herramienta cualitativa}

Como técnica cualitativa para la obtención de información (o datos) optamos por los grupos de discusión. La investigación a través de los grupos de discusión ha tenido un profundo desarrollo en España, fundamentalmente a través de los trabajos de Ibáñez $(25,26,27,28,29)$. Hemos seguido en este trabajo los presupuestos de Canales y Peinado (27) basados en el trabajo de Ibáñez. Los enumeramos de forma muy esquemática de la siguiente forma:

1. La conversación de cada grupo debe entenderse como una totalidad.

2. El papel del moderador será dinamizar el grupo permitiendo que el discurso fluya entre los participantes.

3. Cada interlocutor no es considerado como una entidad, sino como parte de un proceso.

4. Por proceso entendemos que las partes que lo componen cambian en el transcurso de la conversación en la misma medida en que se va organizando y cambiando el todo.

Los grupos de discusión, tal como se describen aquí, es el instrumento a través del cual se intenta que la voz de las personas tenga un espacio. Esta técnica, en tanto que la persona se siente amparada en un grupo, puede permitir, estimulada por el discurso inmediatamente anterior, que se genere una cadena de significaciones. Esta cadena se significaciones cobran sentido en tanto se entiende que es la producción de un grupo, y no la suma de discursos independientes (individuales), la que se va a analizar.

\section{Configuración de los grupos}

En nuestro estudio participaron 43 mujeres que se distribuyeron en 9 grupos de discusión. La muestra se obtuvo de dos dispositivos asistenciales: Un Centro de Salud Mental (Grupos: GD1 a GD5), y el CARRMM: «Centro de Atención, Recuperación y Reinserción de Mujeres Maltratadas» (GD6 a GD9).

El «Centro de Atención, Recuperación y Reinserción de Mujeres Maltratadas» (CARRMM) es un recurso inaugurado en 1991 por la «Federación de Mujeres Separadas y Divorciadas» para mujeres y niños/as víctimas de la violencia de género que orienta 
sus objetivos a la intervención integral. Proporciona, además del acogimiento, un programa estructurado en cinco áreas de trabajo: jurídica, psicológica, formativa, trabajo social y convivencia. Asimismo se realiza apoyo a sus hijos, con el doble objetivo de realizar atención directa a las secuelas del maltrato y prevenir el aprendizaje imitativo de los roles maltratador/víctima. El recurso funciona en régimen de residencia. El periodo de estancia en este recurso puede prolongarse hasta 18 meses.

Las mujeres que habían acudido al Centro de Salud Mental lo habían hecho por motivos diferentes a los malos tratos, habiéndose detectado la presencia de los mismos (físicos) en una investigación previa de Polo Usaola (30).

Los criterios de inclusión de las participantes en los grupos cuya muestra se obtuvo del CSM fueron:

- Mayores de 18 años. Casadas o que hubieran estado casadas, que convivieran o hubieran convivido en pareja.

- Se incluyeron todos los diagnósticos de la clasificación CIE-10, excepto los señalados como criterios de exclusión.

- Que hubieran presentado signos de maltrato físico después de haber realizado escalas específicas de detección $(31,32)$.

Los criterios de inclusión de las mujeres que residían en el CARRMM fueron los mismos salvo que no era preciso el uso de una escala de detección pues eran mujeres ya residentes en un recurso específico.

Los criterios de exclusión eran diagnósticos e iguales para todos los grupos. Se excluyeron aquellas mujeres que presentaban según la CIE-10 diagnósticos de trastorno mental orgánico (F00-09); Esquizofrenia, trastorno esquizotípico y trastorno por ideas delirantes (F20-F29); Episodio depresivo grave con y sin síntomas psicóticos (F31.4, F31.5, F32.2, F33.2, F33.3) y Episodio maniaco (F30, F31.0, F31.1, F31.2, F31.6).

La elección y conformación de estos grupos buscaba una alta representatividad de las experiencias. Ciertamente en los grupos predominaban mujeres que estaban separadas o en proceso. Aunque había grupos de mujeres que convivían con un maltratador -dos grupos-, buscábamos la creación de una teoría, y pensábamos que la perspectiva de la distancia podía constituir un factor clave que podía ayudar, desde la comprensión del proceso en distintos momentos existenciales, la construcción de las narrativas de las participantes. De ahí que el factor: intervalo tiempo de la convivencia (incluyendo convivencia y ruptura), como puede observarse en el diseño de los grupos, fuese la dimensión principal utilizada para su configuración. Aspectos como la edad o el nivel económico no eran necesarios para el diseño cualitativo de este estudio, pues como tal primaban la experiencia y la capacidad de expresarla.

Finalmente los nueve grupos participantes tenían las siguientes características: - Grupo 1 (GD1): Compuesto por 6 mujeres, separadas hacía más de un año. 
- Grupo 2 (GD2): Formado por 5 mujeres que convivían con su pareja y habían sufrido maltrato físico en el último año.

- Grupo 3 (GD3): Compuesto por 4 mujeres que convivían con su pareja pero el último episodio de maltrato físico había ocurrido hacía más de un año.

- Grupo 4 (GD4): Formado por 3 mujeres separadas hacía menos de un año.

- Grupo 5 (GD5): Compuesto por 5 mujeres separadas hacía más de un año.

- Grupo 6 (GD6): Formado por 4 mujeres que habían residido en el CARRMM hacía más de un año y habían completado el proceso individualizado de tratamiento.

- Grupo 7 (GD7): Compuesto por 6 mujeres residentes en dicho dispositivo y que llevaban en el mismo un periodo de tiempo comprendido entre 4 y 6 meses.

- Grupo 8 (GD8): Formado por 4 mujeres que llevaban un periodo de estancia y tratamiento en el Centro entre 7 y 12 meses.

- Grupo 9 (GD9): Formado por 6 mujeres residentes en el Centro de Recuperación Integral por un periodo entre 13 y 18 meses.

Salvo las mujeres incluidas en los grupos GD2 y GD3, las participantes estaban separadas legalmente. Todas las mujeres, excepto dos pertenecientes a los grupos 1 y 9 , tenían hijos. La media fue de 1,9 hijos por mujer participante. Todas las mujeres fueron informadas del estudio y se les pidió consentimiento verbal para el mismo. El proceso de información de la naturaleza del estudio se registró en las grabaciones y fue transcrito.

El número final de grupos se determinó cuando la información obtenida por esta herramienta comenzó a alcanzar para nuestro propósito de investigación la llamada «saturación teorética» (33). Se habla de ello, cuando la incorporación de nuevos datos o de nuevos participantes no aporta más información a un tema que ha llegado a la máxima capacidad de exploración con la metodología elegida.

Tras configurar el posible grupo, contactábamos con las personas propuestas. $\mathrm{Si}$ bien no se explicitaba el objetivo concreto de la investigación (mantenimiento en una situación de maltrato), sí les exponíamos que tenía que ver con el estudio de la violencia de género. De las 29 mujeres en total contactadas para la participación en los distintos grupos provenientes del Centro de Salud Mental, siete, no acudieron, disculpándose el mismo día.

Tras acordar una cita y llamar el día anterior para recordarla, quedábamos emplazados con las participantes en un lugar lo más «neutro» posible. Así con los grupos que provenían del Centro de Salud Mental, el lugar convenido era un dispositivo perteneciente al servicio, pero ubicado en otro lugar del distrito. Este era un centro de Día de Rehabilitación que no estaba operativo por la tarde cuando realizábamos las entrevistas. 
Para los grupos provenientes del Centro de Atención, Recuperación y Reinserción de Mujeres Maltratadas CARRMM, se convino un local en el centro de Madrid, alejado del Centro de Atención de origen. Algunas mujeres sólo habían acudido ocasionalmente a este espacio, pero no era éste el lugar donde hacían gestiones de tipo legal o se hacían entrevistas preliminares para entrar en el CARRMM.

Uno de los miembros del equipo investigador ejercía la función de moderador. Una serie de temas, convenidos previamente, o que eran sugeridos durante la entrevista, eran propuestos en una forma abierta, en el sentido de no inducir ningún tipo de respuesta. Estas intervenciones intentaban ser lo menos numerosas posibles para no interrumpir la espontaneidad y fluidez del discurso. Posteriormente a la finalización de los grupos, los investigadores continuaban reunidos comentando el curso de la entrevista y compartiendo notas tomadas durante el desarrollo de la misma. Esto servía de retroalimentación para el desarrollo y gestión del siguiente grupo.

Se obtuvieron cerca de 17 horas totales de entrevistas que fueron transcritas literalmente.

Se utilizó para la codificación el programa ATLAS.ti (Visual Qualitative Data Análisis Management Model Building) en su versión Win 4.2. (34). Este programa creado por Thomas Muhr, un psiquiatra volcado en la aplicación de la investigación cualitativa a todos los campos de conocimiento, diseñó un programa que facilitaba la interpretación de los textos, las imágenes y el material en audio. Este programa había sido diseñado inspirado en el modelo de la «teoría emergente». Siguiendo la clasificación de Miles y Huberman (35), este programa se puede incluir dentro de los llamados «constructores de redes conceptuales», ya que ayuda a verificar teorías a través de redes gráficas que vinculan conceptos entre sí por medio de relaciones del tipo «pertenece a», "conduce a», «es un elemento de», «contradice a», etc, u otros sistemas de relaciones que el propio investigador puede crear, como en nuestro caso «se atribuye a», o «favorece a», etc. Sea cual sea la completud del programa empleado, la selección, nominación y relación de códigos y categorías siempre se establece por el investigador.

Análisis de los datos: uso de los presupuestos de la Teoría Emergente (Grounded Theory) de Glaser y Strauss (23) para el desarrollo de una teoría del objeto de investigación.

Desde el trabajo original de 1967 han surgido variaciones de enfoque que no han debilitado su esencia; para Charmaz y Mitchel (36), todas las variantes de la teoría emergente incluyen las siguientes estrategias:

1. Colección de datos y su análisis simultáneo.

2. Búsqueda de temas emergentes desde los primeros datos analizados.

3. Descubrir procesos básicos sociales dentro de los datos. 
4. Construcción inductiva de categorías abstractas que expliquen y sinteticen estos procesos.

5. Integración de las categorías dentro de un armazón teorético que especifique causas, condiciones y consecuencias del (los) proceso/s.

Fases de la investigación y participación de los investigadores.

1. Diseño de grupos de discusión y desarrollo de los mismos. Participación en el diseño de todos los investigadores.

2. Transcripción.

3. Codificación y categorización según la teoría emergente (grounded theory) por el investigador principal.

4. Revisión continúa y consenso de los códigos y categorías por el equipo de investigadores.

6. Generación de propuestas teóricas por el investigador principal.

7. Revisión y consenso de las propuestas teóricas entre los investigadores y formulación teórica final.

\section{RESULTADOS}

- La puesta en práctica por el maltratador de una serie de estrategias coercitivas sobre la víctima.

El concepto de «estrategias» ha sido empleado por otros autores, Inmaculada Monzón (37) afirma: «El agresor que niega su responsabilidad en la violencia que ejerce contra su mujer no está en condiciones de modificar el tipo de interacción que tiene con ella pero, por la función que ésta cumple en su vida, no se puede permitir perderla, de modo que va a desarrollar todo tipo de estrategias para someterla, diezmando sus capacidades para romper la relación y conduciéndola hacia estrategias defensivas de permanencia de ella, a la vez que él adquiere mayor control y poder».

Según la R.A.E. (38), la estrategia es un proceso regulable, conjunto de las reglas que aseguran una decisión óptima en cada momento. Esta definición significa la posibilidad de cambios entre diversas estrategias, determinando siempre la más idónea para alcanzar el mismo objetivo. Así, la violencia física se puede transformar en descalificaciones o en amenazas veladas, desconcertando siempre a la mujer, quien sólo ve distintos comportamientos (físicos, verbales), pero no el mismo objetivo que comparten.

1. Sobre la «intencionalidad» del maltratador

Proponer la existencia de estrategias implica hablar sobre la intencionalidad del maltratador. Entendemos que el maltrato es intencional en tanto se dirige a un objetivo: sometimiento de la víctima. Necesariamente, el maltratador no despliega el conjunto de estrategias como un proceso aprendido de antemano. 
Por ello, desde un primer momento, son los distintos actos violentos los que van a conformar el resto del proceso. Las secuencias temporal (proceso reiterativo e impredecible) y espacial (progresivo aislamiento sociofamiliar) son impuestas por las necesidades del agresor y modulan su desarrollo siguiente.

A partir de aquí, a modo de un proceso de perfeccionamiento, se produce lo que Lorente (39) describe en los siguientes términos: «(...) el agresor, en muchos casos, necesita un tiempo para encontrar lo que podríamos considerar «su forma de agredir»; aquella en la que él percibe que se ha alcanzado el equilibrio de efectividad, eficacia y seguridad».

\section{Sobre la «necesidad» del maltratador}

Autores como Dutton y Golant (40), basándose en las teorías de las relaciones objetales y las teorías del vínculo proponen que los hombres violentos presentarían el mismo perfil de las conductas de niños que no han alcanzado adecuadamente la cuarta fase de Margaret Mahler $(41,42)$.

Para estos autores, estos hombres violentos buscan así mujeres a quienes puedan dominar, sobre todo en el sentido de decidir la distancia emocional en la relación. Esto podría tratarse de un medio de manejar el trauma original de un acercamiento fallido. Pero a su vez, este intento de dominio generaría ansiedad e ira. Si el control se ve amenazado, la ansiedad y la ira hasta entonces ocultas aflorarían a la superficie.

Jukes (43) propone la teoría de la «burbuja», según la cual el maltratador vive en un «self privado»: «La cualidad esencial de esto es que el hombre tiene una vida mental privada la cual nunca comparte con otros».

La burbuja se formula como una encapsulación defensiva del sí mismo, que permite mantener a la realidad y a las personas lejos sin sentirse amenazado por percepciones que contradigan las estructuras cognitivas, las actitudes, creencias y valores propios. Así, «no existe realidad analizándose en la burbuja, sólo hostilidad».

Para Jukes, en general, los maltratadores, interpretan su propio comportamiento como pasivo, más que como una respuesta a la forma en que los demás le traten a él.

Según este autor, el origen de la burbuja en la que vive el maltratador, es un proceso que se generó en las fases más tempranas de la infancia. Se basa para ello en los trabajos de Balint (44):

«Es en definitiva una relación entre dos personas en las cuales, sin embargo, sólo uno de los miembros importa; sus deseos y necesidades son las únicas que se tienen en cuenta y que deben ser atendidas; el otro miembro de la pareja, aunque sentido como un ser inmensamente poderoso, importa sólo en la medida 
en que está dispuesto a gratificar las necesidades o deseos del primero o decide frustrarlas; más allá de esto sus intereses personales, necesidades, deseos ilusiones, etc, simplemente no existen».

Para Jukes (36), la «falta básica» es una condición esencial o necesaria para el abuso de las mujeres por los hombres, pero no suficiente. La cuestión no es ya si ella le frustra o no a él. Lo importante es la percepción que él tiene desde su burbuja, y a la cual, como los demás ella no tiene acceso. Así, basta que ella tenga una necesidad, ilusión o deseo para ser percibida como amenazadora de su integridad.

3. La dependencia del maltratador se materializa como control sobre la víctima La permanencia del control del maltratador se mantiene a lo largo de todo el proceso. Llorente (32) afirma: «"En el caso de los maltratadores, todos necesitan el control de la mujer (...). El agresor que agrede a la mujer da muestras de tener una conducta perfectamente definida y destinada a la consecución de un objetivo concreto, y por ello se aprecia que en todo momento es consciente de lo que está haciendo, sabe por qué y para qué lo hace y siempre manteniendo el control de la situación (...)».

Este control del maltratador se realiza a través de la repetición de las estrategias coercitivas. Por medio de este comportamiento de acoso, el maltratador «se» hace presente a la víctima a través del tiempo. Este control permanente sobre la víctima, sugiere una dependencia del maltratador «de» su víctima.

- Yo pienso que son muy inteligentes. En mi caso yo lo digo y al hablar con las compañeras eran maquiavélicos, o sea, es todo planeado, es planeado para que nunca te vayas de su lado, o sea, para tenerte ahí y para que dependas de ellos, porque si te pierden, pierden el control (GD7)

- y yo también he pensado que nos retenían, a mi personalmente, nos retenian porque te necesitaban, te necesitaban en el sentido de... - Porque son inútiles. -... en el sentido en que..., es que ellos sin ti, como te machacaban, se sentían poderosos o superiores, podian contigo. (GD7)

4. Control del maltratador y comportamientos celotípicos.

Este rasgo celotípico se encuentra en muchas de las tipologías de maltratadores $(40,45,46,47)$.

Sin embargo, más que el clásico delirio celotípico de infidelidad, en nuestros datos abundan las descripciones de manifestaciones celotípicas que parecen aludir a la no aceptación de la presencia de una tercera persona. Este «tercero» es vivido por el maltratador como una amenaza a la relación dual y exclusiva que establece con su pareja. Este riesgo de ruptura de la relación diádica puede hacer emerger sentimientos ontológicos de inseguridad. 
O sea, tenía celos de que no le quisiera sólo a él... (GD1)

... yo lo de celos con otros hombres, no,... que se metía conmigo y que era tonta y todo eso... Pero en el fondo era como... ahora lo veo... como los niños pequeños, que le has dejado de hacer caso a él y le has destronado porque han venido... ha venido otro. 0 sea, te llevas muy bien, nos casamos y nada mas tal... estábamos embobados, cuando... yo también le aparté un poco porque empecé a tener hijos. Lo veo ahora...es que no tenía otra... (GD1)

Esta tercera persona que irrumpe, significa un riesgo para la relación de dominación y aleja la atención de la víctima de él.

... -Tenía celos de mis nietos, de mis hijos, de mis hermanos, hasta de las vecinas que he saludado... -No eran celos porque fuera por otro hombre, ni porque tuviera celos del vecino, del carnicero... (...)... celos horribles de mi familia, sobre todo de mi hermano. (GD1)

La no aceptación de «un tercero» podría ayudar a explicar por otra parte, el elevado número de descripciones que fueron recogidas en nuestro estudio -fenómeno ya descrito cuantitativamente en investigaciones previas- sobre el inicio de acciones violentas cuando la mujer se encontraba embarazada $(48,49,50,51,52)$.

(...) cambió casi de la noche a la mañana después de tener el niño, o sea, que... fue algo terrible. Moderador: ¿Qué pasó? - Pues sí, al mes de tener el niño, la primera bofetada, o sea, que fue un cambio..., hasta entonces, pues normal (entre comillas). - Sí, yo fue al quedarme embarazada cuando empezó. Moderador: ¿Al quedarte embarazada también? - Al quedarme embarazada fue cuando yo empecé a percibir que algo había cambiado (...) y empezó, pues eso, a salir, a no venir o a aparecer con los amigos sin avisar, a decir «es que tú eres un rollo, porque no puedes beber, o no quieres salir a bailar porque tu ropa no te cabe», empezó eso ya cuando me quedé embarazada la primera vez...(GD6)

Pero las agresiones fuertes han sido ya de casados, con críos, con el primer embarazo empezaron las agresiones fuertes. (GD7)

- Estrategias de control

Las estrategias de control o de coerción actúan entre sí de una forma sinérgica. El modelo coercitivo en la violencia de género se iniciaba según nuestros datos a partir de tres estrategias básicas:

- Actos violentos. Definen la relación. Las formas de manifestarse la violencia se relacionan entre sí, concurren y/o se alternan. Así, es imposible concebir actos de violencia «puros», sin implicación emocional. De ahí que la distinción entre maltrato físico y emocional sea un tanto artificial. La presencia de actos violentos son obligatorios para definir la relación de violencia de género, pero no suficientes para comprender el proceso. 
- Modulación del tiempo en el que se ejercen los actos violentos: La segunda estrategia, por la cual el maltratador actúa según sus necesidades o frustraciones, es la modulación del tiempo. La víctima así es sometida a un proceso continuo de violencia, pero en el que irrumpen agresiones impredecibles, o fases de recrudecimiento que crean la ficción de «ciclos» en los que la «calma» y la violencia se alternan.

- Aislamiento: El aislamiento, aunque nos evoca formas físicas en la cual la persona no tiene acceso a otras personas o a recursos propios, ha de comprenderse también como aislamiento en tanto imposibilidad de comunicar vivencias y emociones. La vergüenza y el sentimiento de culpa favorecen que la víctima oculte el maltrato al que está siendo sometida.

Esta modulación de «tiempo y espacio» genera confusión en la víctima. Sin embargo, para entender bien el proceso de la violencia es necesario comprender que realmente el control sobre el tiempo y el espacio se hacen continua y simultáneamente. Realmente no existe periodo sin efecto de la violencia. Dado el gran impacto que genera la agresión física, esto puede determinar que la mujer entienda periodos de descalificaciones sin presencia de acciones físicas o accesos de cólera verbal, como ausencia de agresividad. En fases más avanzadas puede haber periodos de «silencio» (se ha alcanzado una economía de la violencia por el agresor), el maltrato impredecible ha facilitado este efecto de incertidumbre constante.

\section{Actos violentos}

a) Categorización de los actos violentos

Utilizamos la denominación de «actos violentos» para esta categoría, dada la ambigüedad de otros conceptos como «agresivo», «violento» y «hostil» (53).

Las subcategorías que componen este grupo fueron denominadas: «acto violento físico (con contacto)», «descalificación y desvalorización», «amenaza» y «violación de la pareja». Mientras el primero y el último son lo suficientemente explícitos y con elementos diferenciables $(54,55)$, los códigos correspondientes a la desvalorización y la amenaza, son identificados muchas veces de forma conjunta como maltratos psíquicos (56).

En nuestro estudio, las amenazas mostraron una capacidad fundamental para generar emociones tendentes a la paralización de la víctima, y con ello disuadir a la mujer de abandonar la relación, lo que las configuraban como una subcategoría específica dentro de los actos violentos.

- Propiedades diferenciales de las amenazas de otros actos violentos

- Suspensión -latencia- en el tiempo con capacidad de proyectarse al futuro. 
- La amenaza remite fundamentalmente a un acto corporal, lo cual la aproxima al acto físico de violencia; de hecho, podríamos definir la amenaza como un «acto físico (virtual) de violencia».

- Se construyen como formas de violencia eidéticas. Ello hace referencia a la tendencia a convertir el pensamiento en imágenes. De esta forma la amenaza puede ser reproducida en y por el imaginario de la mujer, pudiendo adoptar la forma de pensamientos intrusivos durante la vigilia y el sueño.

Incluso muchas veces he soñado y de esto que estás sentada, o sea, que tú estás como pensativa, me he visto muerta, aunque sea muy fuerte decirlo es asi, yo lo he sentido. $Y$ en sueños me he visto que me mataba. Y un sueño incluso fue tan real que yo, o sea, me veía ya morir, sin fuerzas, no sé a lo mejor es que mi mente me ha jugado una mala pasada por todo esto que he pasado, pero yo me he sentido morir en sueños. $Y$ de estar pensando y pensar que me lo puedo encontrar en un parque y verme muerta en ese parque, ver cómo me mata. (GD8)

- Pueden utilizar cualquier medio de comunicación con la víctima. La amenaza es fácilmente reconocible por la víctima, ya que emplea un lenguaje universal (así, pasar un dedo por el propio cuello, remite a la «imagen» de muerte, de igual forma que apuntar con el dedo índice «reproduce» un arma de fuego).

- Niegan que con la separación finalice el maltrato. La amenaza consigue este efecto gracias a su proyección -posibilidad de materialización- a través del tiempo.

- Yo tengo miedo a que nunca va a acabar, porque él me tiene amenazada (...) (GD7).

- Gran parte del poder disuasor de la amenaza estriba en que es difícil aceptar el riesgo de comprobar si quien la emite puede cumplirla.

- La amenaza en la violencia de género tiene mayor riesgo de materializarse cuando su función principal se concentra en disuadir a la víctima de abandonar la relación. La multitud de veces en que las amenazas son cumplidas y se muestran los femicidios en los medios de comunicación, manifiesta su capacidad para convertirse en una posibilidad contrastada por la realidad, perdiendo así su carácter ilusorio.

- En nuestro estudio, las amenazas generalmente eran vagas, expresando un daño en el futuro que no se detallaba, salvo en dos expresiones concretas: amenazas de muerte y amenazas de quedarse él en «posesión» de los hijos. De los once fragmentos en los que detectamos que claramente el objetivo de la amenaza era disuadir a la mujer de 
separarse, salvo en uno de ellos, en todos el maltratador utilizó como amenaza quedarse con los niños (ocho), la posibilidad de matarlo (uno) o infringirle un daño indefinido (uno).

Ellos creen que como a ellos, o sea, es cierto que un padre te diga: «Pues como venga la policía y me lo quiera quitar, lo tiro por la ventana», o sea, eso a él, bueno, quiero decir cómo puede entrar en la cabeza de estas personas, pero, o sea, yo la manera de verlo es que no me lo explico, no es la capacidad de decir que la madre..., tú no lo vas a permitir porque eres su madre, porque lo quieres, pero a él le da igual decirlo, y si lo dice es porque lo va a hacer. (GD6)

b) La alternancia entre los actos de violencia.

Todas las formas de actos violentos suelen combinarse. Los actos violentos físicos acontecen en un contexto de amenazas y desvalorizaciones; las violaciones intramaritales se realizan bajo formas de coacción, amenazas y muchas veces como forma de humillación; o, pueden existir desvalorizaciones continuas sin actos violentos físicos, si bien suelen combinarse con amenazas. ... aparte de las palizas y de los tratos violentos, eso ya como que, bueno, si pasaban más de dos semanas sin eso decía: «Bueno, se ha pasado». 0 sea, vamos a ver, vives en otro mundo, pero vives así, una de cal... - En una montaña rusa. - ... exacto, y otra de arena, si pasaba una semana o dos semanas sin violencia fisica, pero no pasaba la violencia psicológica, porque yo seguía siendo una inútil, una madre que no sabía nada, que no sabía comprar, que tú compras con los ojos, o sea, yo no sabía..., era una maleducada venida del este que no sabía ni cocinar, bueno, o sea, pero era espantoso, y eso pues oírlo más o menos de diferentes maneras, pues no sé, quizá es imposible que te hagas una idea, y entonces vivir en esta balanza. (GD6)

La constancia o interrupción de una forma de violencia en el tiempo es una propiedad inherente al propio acto; así, mientras malos tratos de carácter físico sin interrupción en el tiempo son incompatibles con la supervivencia, las descalificaciones y desvalorizaciones pueden mantenerse a lo largo de todo el proceso. Las amenazas, para conservar su eficacia suelen ser racionadas en su uso.

2. Estrategias derivadas del predominio de la modulación del tiempo en la aparición de los actos violentos.

Como haremos hincapié en otros apartados, los actos de violencia físicos requieren por su propia naturaleza una distribución en el tiempo, so pena de destruir definitivamente a la víctima. Realmente el control de él y la violencia que lo acompaña son continuos en todo el proceso. Podemos decir que sobre dicho «ruido 
de fondo» (violencia de fondo), surgen exacerbaciones de actos violentos verbales y físicos que no pueden ser anticipados por la mujer, y fases de mayor violencia que generan la ilusión de ciclos definidos que se alternan con (supuestos) periodos de calma. La violencia física también se desarrollará en el aislamiento del hogar, pero su efecto más intenso lo obtendrá de la imposibilidad de su predicción por la víctima.

a) La estrategia del maltrato impredecible y su percepción como «comportamiento caótico»

La capacidad de predecir los sucesos es inherente al desarrollo cultural humano, y en gran medida se ha comprendido como un factor de supervivencia. La imposibilidad de predecir un acontecimiento traumático que se repite con frecuencia en el tiempo genera un fuerte sentimiento de vulnerabilidad. El maltrato impredecible activa un estado de alerta y de estrés constante en la víctima. Según la teoría de la «indefensión aprendida» formulada por Leonore Walker (6), basada a su vez en el concepto de Seligman (7), el comportamiento violento impredecible generaba un estado de pasividad que imposibilitaba escapar a la mujer de la relación. Nuestros datos arrojan correcciones a esta teoría que explicaremos más adelante. Esta imposibilidad de anticipación y control sobre la violencia fue codificada por nosotros como «maltrato impredecible».

Esta impredecibilidad, hace percibir a la mujer el comportamiento de él como «caótico». Esto genera un estado de sorpresa; estado que se aplica no sólo a los episodios agresivos, sino a los cambios de carácter y de humor, o ante una sorpresiva mala contestación. La mujer todavía no percibe que esos «pequeños gestos» son ya «signos» de una violencia global. En las primeras etapas de la relación, la mujer experimenta estos conatos agresivos de su pareja como episodios aislados, desconectados de otros momentos de violencia. El código «comportamiento caótico» fue utilizado para catalogar todas esas experiencias de asombro y de confusión que se desencadenan en la víctima. Digamos que el maltrato impredecible, se presenta ante la mujer como comportamiento caótico, y ello, no le permite ver el hecho irreductible del acto violento que está detrás.

Esto lo consideramos clave, pues supone una dilatación en el tiempo de la confusión antes de que la mujer pueda percibir que existe un franco maltrato. Ello facilita que otras estrategias se vayan instalando y definiendo en la relación violenta.

Durante las primeras etapas de la relación, la mujer intenta comprender estos cambios de humor o respuestas intempestivas (justificándolas en numerosas ocasiones). En fases posteriores, intentará determinar un patrón predictivo 
o un catálogo de conflictos que permitan identificar el riesgo de la agresión. De esta forma, el asombro desaparecerá conforme se desarrolle la emoción del miedo.

La descripción de las mujeres de sus reacciones de asombro ante las conductas «caóticas» permite formular una secuencia en el tiempo de búsqueda (y fracaso) de un sentido a las mismas.

- Experiencia de asombro (o sorpresa)

... Yo como tengo un carácter totalmente distinto al suyo él empezaba a gritarme y yo... a mí me resultaba sorprendente ... porque no estaba acostumbrada a que él me gritara ... bueno, pues, yo iba callando pero eso iba cada vez a más, cada vez a más... (GD2)

Esta experiencia con sus efectos es muy similar a la descrita por Sluzki (57) como «disonancia cognitiva». Esta ocurriría en una situación de violencia de baja intensidad, como parece que se produce al inicio de la relación: «la reacción que se produce es de sorpresa, de imposibilidad de integrar este hecho en la experiencia. Se produce una autoprotección y se trata de sobrevivir al suceso. Es frecuente que aparezcan reacciones de shock, negación, confusión, abatimiento, aturdimiento y temor».

- Búsqueda de una explicación

Pero, al principio, me volvía loca pensando, ¿que será?, ¿qué... qué es lo que sucede? (GD2)

Fracaso en la búsqueda.

Yo me decía... yo no puedo aguantar lo suficiente... o estar a la altura suya o porque yo... en fin. $Y$ era tan, tan, que era por todo... y... y... yo me desorientaba porque decía señor si yo intento hacer lo mejor posible, si yo quiero... (GD1)

A veces esta ansiedad se percibe como más dañina que el propio acto violento, provocando un estado de hipervigilancia:

A mí me pasa igual que a ella, que más que los tratos, los malos tratos físicos, las dos ó tres bofetadas, (es) el estrés de estar pensando «y como vendrá y como no vendrá, si me tocará hoy, no me tocará». (GD5)

- Intento de acierto por azar. Ante la imposibilidad de acierto, al no poderse encontrar un patrón de conductas, o indicios que predigan el maltrato, se renuncia a la búsqueda de sentido. Se intentan ya distintas conductas (sin una teoría de la víctima que las sustenten y que eviten la agresión). Si es que no das una... hagas lo que hagas no das una... (GD1)

b) El maltrato impredecible y la indefensión aprendida Inicialmente, consideramos ambos términos como equivalentes. El modelo de indefensión aprendida, tal como lo aplicó Walker, establecía una relación directa entre el «maltrato impredecible» y la «inmovilización y paralización». 
Conforme avanzábamos en el análisis, encontramos lo que se antojaba como una contradicción a dicha asociación lineal: mientras en nuestros datos se apreciaban relaciones directas entre el «maltrato impredecible» y el miedo, y entre esta misma emoción y la «inmovilización y paralización», el «maltrato impredecible» y la «inmovilización / paralización» no parecían relacionarse directamente entre sí. Lo que encontramos realmente, fue que una emoción, el miedo, se encontraba entre el «maltrato impredecible» y la «inmovilización / paralización».

«Maltrato impredecible» $\longrightarrow$ «MIED0 (terror)» $\longrightarrow$ «InmovilizaciónParalización»

- Miedo y maltrato impredecible:

$Y$ después cuando llegaba a casa pues ya eran broncas por todo, y venga a decir «que de donde venía, que donde había estado, que si el autobús había tardado, que si el autobús...». Siempre pues claro, cosas que, que, y con miedos y yo en el autobús decía, «que, cómo llego, cuando llegue, cuando llegue cómo me lo encontraré hoy, cómo, ¿lo encontraré de buen humor o no lo encontraré de buen humor?», y yo iba siempre muy nerviosa. (GD5)

- Miedo e inmovilización/paralización:

- Ya no es el miedo, el pánico que le llegas a tener a esa persona, porque yo recuerdo una vez que estaba yo con el niño en la calle, y pasaba gente al lado, pero yo era como un..., que no tienes vida, como que sólo le oyes a él. 0 sea, que tú quieres..., en tu casa te pasan un montón de cosas, es decir, pues qué hago de esto, y si me voy para allí, y si corro, pero no lo haces, o sea, estás todo el rato pensando, pero de ahí no sales... (GD6)

Una posible respuesta a esta contradicción con la teoría original de Walker la encontramos en Peterson, Maier y el propio Seligman (58) cuando, años después de la monografía del último autor, revisaron el impacto de la teoría de la indefensión aprendida, incluida su vinculación con el síndrome de la mujer maltratada. Para estos autores, la aplicación al maltrato de la indefensión aprendida que Walker había hecho era incorrecta, y sólo daba cuenta parcialmente del fenómeno.

Consideraban que la pasividad que se describía entre víctimas de la violencia doméstica podía tratarse más bien de un efecto instrumental. Las cogniciones de indefensión estarían presentes como corresponde a un contexto incontrolable, pero podían deberse también a una historia de reforzamiento explícito de la pasividad. 
Por otra parte, a diferencia del escaso peso que había tenido el miedo en la monografía original de Seligman, esta emoción cobraba ahora un papel preponderante en la revisión del concepto. De hecho sería el miedo lo que era generado por la indefensión aprendida. Por otra parte, la paralización podría ser efecto de numerosos elementos cognitivos, no de la indefensión aprendida. Estas discrepancias con el modelo de Walker eran coincidentes con nuestros datos y nos ofertaban una nueva forma de comprenderlos. La propuesta sería entonces que el maltrato impredecible generaba miedo, el cual actuaba junto con otros elementos (de forma parecida a como lo expresaban Peterson, Maier y Seligman) para provocar un efecto de inmovilización.

En esto nos basamos para considerar que el concepto de «indefensión aprendida» no tiene la capacidad explicativa que en un momento le otorgamos, más aun cuando el propio concepto de inmovilización en la mujer como sinónimo de pasividad, debe revisarse.

c) El «ciclo de la violencia» y el «maltrato impredecible» Leonore Walker $(6,59,60,61)$ desarrolló la idea de que el maltrato hacia las mujeres tenía un carácter cíclico.

Los ciclos de violencia son asimismo impredecibles, pues aunque la mujer perciba el aumento del nivel de tensión, no ha podido prevenir la aparición de dicho ciclo, y tampoco podrá prevenir dentro del mismo el inicio del ataque. Realmente, el ciclo de la violencia es una forma de maltrato impredecible. Es la presencia o no de la estrategia del arrepentimiento, intercalada entre los episodios de agresión la que genera la ilusión de una periodicidad. Pero el inicio de la fase de tensión, el momento de su descarga en forma de violencia, y la declaración de arrepentimiento, son iniciadas siempre por el maltratador y nunca pueden predecirse por la víctima. Conforme se consoliden las distintas estrategias de maltrato, la estrategia de arrepentimiento escaseará cada vez más y los ciclos de violencia irán perdiendo presencia.

Siendo un concepto ampliamente desarrollado en nuestro trabajo pero con numerosos referentes en la literatura, destacaremos aquí sólo una estrategia vinculada a nuestro objeto de investigación: la que hemos denominado «estrategia del arrepentimiento».

- La «estrategia del arrepentimiento»

El arrepentimiento que oferta el agresor, hace abrigar a la mujer la esperanza de que su proyecto de una relación de pareja pueda sobrevivir. (Sin embargo, esto otorgará de nuevo tiempo para que el proceso de maltrato se vaya consolidando). Este arrepentimiento confluye con la negación o la justificación de las conductas de él que realiza la mujer, siendo estos mecanismos desarrollados por ella para preservar la «ilusión» de que la 
relación, sin violencia, puede existir como proyecto vital. Desarrollaremos en mayor extensión esta estrategia y los mecanismos cognitivos y emociones implicadas en el segundo artículo que completa este estudio.

\section{Aislamiento}

Como seres eminentemente sociales, los humanos percibimos que todo aislamiento ambiental implica un aislamiento emocional. Según el Diccionario de la R.A.E. (38), aislamiento en su sentido figurado significa incomunicación y desamparo.

a) El aislamiento como estrategia

Cuando hablamos de aislamiento en violencia lo hacemos en alusión al espacio psíquico. El aislamiento físico es una instrumentalización cuyo fin último es el confinamiento mental, esto es, la separación de la mujer de cualquier otro referente externo al propio maltratador. Los celos ejercen este efecto, de igual forma que lo hace el aislamiento físico. El aislamiento constituye la estrategia más comúnmente recogida en toda la literatura. Funciona como el crisol en el cual, perdidos para la víctima los referentes externos, el maltratador actuará libre de cualquier injerencia y materializará su deseo de una relación dual exclusiva (62).

Sin embargo, en las primeras fases de la violencia, la mujer percibe que sufre un aislamiento fundamentalmente físico. La víctima no ha desarrollado todavía una deconstrucción de su identidad que se generará en fases más avanzadas.

- Así, el aislamiento se inicia desde las primeras fases de la relación.

En mi caso fue con el noviazgo, ya empezó a apartarme, de amigos sobre todo, y luego ya de la familia, a nivel de descalificar a mis amigos, descalificar a mi familia, sentirse celoso de amigos ( ). (GD9)

- Al principio el aislamiento parece formar parte del mismo juego de seducción que establece el maltratador al inicio de la relación, «valorándola»o halagándola:

... - Muy sutil. - ¿Qué dónde vas a ir tú? - Que esos amigos no son para ti. - Esas amigas, ésas son unas putas, y entonces... - Sí, más o menos. - 0 la familia. - No, pero todo por miedo. 0 sea, que cómo te vas a hablar con esa gente, tú mereces otra calidad de vida, ya te presento a mis amigos... - Exacto. - ... valorándote a ti, o sea, rechazaba a los otros, pero diciendo: yo quiero algo para ti, para tu bien... - Exacto. iAy, cómo vas a aceptar ese trabajo! Y me decía: ay, si tú eres... - Claro. 0 sea, todo, te valoraba en el fondo y decías: hombre, si lo hace por mí. (GD6) 
Bajo este supuesto halago, existe una descalificación sobre otras personas y sobre ella misma: estás con «putas» o con mala gente. Esta afirmación busca confundirla y al mismo tiempo aislarla.

- Un elemento clave del aislamiento es desposeerla de medios económicos. Luego también se crea la dependencia económica, porque uno de los factores que se encargan de manipularlo muy bien es el que te quedes sin defensa, sin defensas emocionales y también físicas. Una de las defensas físicas es el dinero. Entonces, en muchos casos, incluido el mío, te pide que dejes el trabajo, si trabajabas, entonces una vez que dejas el trabajo te quedas sin sustento económico, con lo cual pasas a pertenecer y a depender prácticamente de él. (GD9)

- La distancia física y el idioma pueden ser factores importantes de aislamiento Él piensa que es mejor llevar al niño a vivir a su país para que aprenda el idioma. Él no me enseñó el idioma, la culpa la he tenido yo, porque yo no sabía hablar el árabe. (GD7)

... me llevaron a (un pueblo de la serranía de Madrid) y me soltaron en una urbanización... (GD1)

- El maltratador intenta apartar a la víctima de su familia al tiempo que intenta introducirla en su entorno.

Yo solamente a su familia, ni a amigas, a nadie, a nadie; a mi gente, a mi familia, todo lo contrario, siempre disculpándole. Mis padres: es el cumpleaños, ¿venís este domingo? Pues como el día anterior sabía que íbamos a ir o que..., claro, como sabía que era el cumpleaños de mi padre, pues ya me liaba una terrible: «Y en tu casa...» y llamaba a mi madre y decía: «ay, mamá, resulta que ha venido Luisa, mi amiga, y tiene un examen el lunes y no podemos ir», eso les decía yo a mis padres, y es por la que había tenido, insultaba a mis padres, me insultaba a mí. Y mintiendo, yo a mis padres siempre mintiéndoles, y a mi hermana. (GD7)

En este fragmento, la mujer maltratada, inadvertidamente había estado fortaleciendo el aislamiento. Intentando minimizar la confrontación que él busca con la familia de ella, le justifica y realiza también un ocultamiento de su actitud. Finalmente para evitar esta confrontación, se aísla junto al maltratador apartándose de su propia familia.

El hogar, donde ella es recluida, se convierte en un lugar hostil

El «hogar» no es el lugar cálido, donde la mujer se protege del exterior. A veces la violencia es silente, $\mathrm{y}$ los propios vecinos muestran un gran asombro cuando un día el horror atraviesa las paredes.

Pero ya, claro, cada vez callaba más, callaba más y en mi casa era como si fuéramos mudos, ya últimamente se me estaba negando a hablar ( ) porque 
sabías que si ibas a hablar algo, porque estaba la televisión puesta y quería oír algo "psss, psss», siempre era montar pelea por todo, bien porque iba a oír la televisión, o porque estaba leyendo el periódico o simplemente porque le apetecía estar en silencio. (GD8)

$Y$ además las cartas que recibía de mis padres y mis amigas, yo no tenía la llave del buzón. Él cogía mis cartas y yo () mis amigas y mis padres que pasaba algo raro, porque yo nunca recibo nada, qué raro. Y yo encontré muchas veces mis cartas en sus abrigos, muchas veces. (GD9)

En un sentido similar Miller (15) hace referencia al aislamiento al que está sometido la mujer como una prisión.

b) El aislamiento psíquico y la deconstrucción de la identidad: la estrategia de la «luz de gas»

Conforme la suma de estrategias va generando un estado de confusión de pensamientos y emociones, el aislamiento psíquico induce una debilitación cognitiva en la víctima.

En un primer momento, el concepto de «lavado de cerebro» nos permitía describir una estrategia que generaba un estado disociativo. En el mismo, la víctima dudaba y rechazaba sus propios sistemas de creencias, adoptando los que sobre ella imponía el maltratador. No obstante, a medida que iba cobrando fuerza la capacidad explicativa de la persuasión coercitiva como generadora de estrategias, ello nos planteaba un problema: la equivalencia que se había establecido por muchos autores entre lavado de cerebro y persuasión coercitiva. Esto se puede explicar por el hecho de que el concepto de persuasión coercitiva se ha utilizado frecuentemente en las investigaciones sobre movimientos sectarios, donde, habitualmente, la violencia física o la descalificación explícita tienen escasa o nula preeminencia. Al igual que en las definiciones antes establecidas entendemos que el lavado de cerebro, tal como lo hemos descrito, es una estrategia más dentro de la persuasión coercitiva. No obstante, con el objetivo de evitar confusiones, aludiremos a los códigos que marcaban estas descripciones con la etiqueta: «luz de gas», título de una conocida película de 1944, dirigida por George Cukor, que relataba perfectamente dicho mecanismo.

El aislamiento busca la anulación de cualquier otro referente que apoye la percepción de ella y cuestione la de él. Como referimos antes, si el sistema de creencias del maltratador es compartido por la familia del mismo, la víctima es «integrada» en dicho entorno. Las descalificaciones, carentes de la intensidad de la violencia física y su imprevisibilidad, requieren de su reiteración en un medio de aislamiento social para alcanzar la capacidad de distorsionar el propio sistema de creencias de la víctima. 
Añadido a esto, por medio de la estrategia de «luz de gas» (lavado de cerebro), el maltratador reinterpreta el origen de la violencia. Así, el «maltrato impredecible» no será a partir de entonces tal, sino la respuesta «apropiada» a la «provocación» de la víctima. La confusión de pensamientos y emociones que por sí genera la estrategia del «maltrato impredecible», es moldeada por el maltratador en el crisol del aislamiento, convirtiéndose la víctima para sí misma en la verdadera culpable de la situación.

- La constante desvalorización de la víctima

La desvalorización se puede permitir algo que sin embargo es incompatible con la violencia física, ser constante. El concepto de mujer, y las distintas asociaciones que tantos estudios han establecido entre el lenguaje y el prejuicio sexista, encuentran dos de sus máximas expresiones en los insultos (descalificaciones) de las mujeres como «putas» o como «locas» (63). Son precisamente estas dos descalificaciones las que con mayor frecuencia son descritas por las participantes en nuestro estudio. La consideración de la mujer como «puta», le otorga al maltratador un argumento de género inscrito en la cultura justificativo para desplegar la agresividad.

Aquí ya sí empiezan mucho más, empieza a tirarme del pelo, a darme patadas, a insultarme cosas de todo tipo, desde que eres una hija de puta, eres una puta, eres una zorra, y bueno aquí ya empieza mucho más. (GD8) El maltratador puede llegar a denominar a su mujer como prostituta ante terceras personas al tiempo que él se proclama como víctima. Puede no experimentar vergüenza por expresarlo ante otros si siente que un gran sector social comparte esta creencia despectiva contra las mujeres. La calificación, expresada por el abusador ante los demás, tiene por otra parte el efecto de aislar a la víctima. Así, ella, acusada y enfrentada a esa connivencia social, se aparta, avergonzada.

Moderadora: ¿Habéis sentido vergüenza? - A mí si me salían por las ventanas los chillidos, o sea, que lo sabían de sobra. - No, yo mentía siempre. - Era porque él me decía a gritos que yo era una puta, que el niño no era suyo, que yo era..., bueno, cosas horribles, y tenía vergüenza de salir de casa y cruzarme con los vecinos, eso sí. (GD7)

Por otra parte, el uso de la palabra «loca» constituye la descalificación total. «Loca», es popularmente aquella persona cuyo discurso no tiene sentido. Cuatro letras bastan para negar a la aludida toda posibilidad de réplica y argumentación. Es un enunciado además con una característica de trampa, pues la víctima antes de poder abordar el origen de la disputa, tiene que, o cree que debe, alegar su cordura. El conflicto pues, como parece habitual se coloca en otro lugar. 
Yera una persona, jamás se me olvidará, para él estaba loca. 0 sea, siempre que me ponía a lo mejor a discutir con él era que yo estaba loca. Y yo creo que llegó un momento en el que me creía que realmente estaba loca. Que me inventaba las cosas. Llegué a planteármelo que si realmente estaba loca. (GD1) Lavado de cerebro y culpa

Si bien la culpa, recibirá una atención especial dentro de un próximo artículo sobre las emociones, es importante su mención aquí, pues nos da idea de en qué forma el maltrato distorsiona las emociones y cogniciones, y las hace retornar «contra» la propia víctima.

El proceso reiterado del «castigo» (violencia) fuerza en la víctima la internalización de:

- Acusaciones sobre conductas no realizadas, pero reprobables desde una percepción y atribución moral del agresor (Ej.: infidelidad).

- La atribución y permutación del acto violento como «acto justo». Este acto violento puede pasar de ser una agresión, a un castigo justificado primero por el agresor (ahora ejecutor), y luego por la propia víctima. ... saben... ... te están pegando y al final... ... este tío inteligente no... ... crees que te lo estás mereciendo... yo me he sentido culpable... ... y a mí una torta y otra... ... y este tío ¿no? Y a lo mejor tú empiezas a pensar y dices, no es que a lo mejor he hecho esto mal y me lo merezco, o sea, al final terminas creyéndote que te estás mereciendo lo que te está ocurriendo. (GD1)

Castigo, o merecimiento remiten a culpa, y a expiación. La duda: ¿por qué me pega?, se transforma en una duda paralizante: ¿soy o no soy culpable? La duda, la pregunta sobre el proceso al cual está siendo sometida se desliza desde una cuestión clave que contempla el papel de él (¿por qué me pega?), a cuestionamientos que sólo remiten a ella (¿puedo ser yo la culpable?).

...y la mañana la pasaba sin poder pararme a pensar, como si tuviera una tormenta de pensamientos, una sensación de... -Sí, porque se rompen los circuitos normales que...- ... no me puedo parar. $Y$ una sensación de no entiendo nada la tenía mucho, no sé qué pasa, y no era capaz de focalizarlo en él, él tiene la culpa, no. 0 sea, a mí me pasa algo y no sé qué es y no ponerle nombre. (GD6)

La víctima se siente por tanto atrapada en una cadena de preguntas sobre sí misma (no ya sobre el agresor), que dificultan que pueda cuestionarse su situación de maltrato.

Yo... es que... he dado mucho al... coco ... para tratar un poco de... de verme cómo... estaba yo frente a esa situación... o sea que... he tratado de analizarme... emm... yo mucho... los primeros tiempos 
yo... decía voy a anotar a ver por qué empieza la discusión, a ver... emm... qué es lo que tengo yo culpa para poderlo remediar... y veía que ... que era imposible, porque era cualquier tontería... si estaba la comida caliente... él no podía soplar... si se quemaba, pues yo tenía la culpa... si estaba fría, estaba fría... (...)... Eran muchas cosas... emm... también... sentía algo como que me trataba de volver loca... él.... Pero decía digo si... si estoy un poco... porque vi la película que no me acuerdo cómo era pero... se llamaba «Luz de gas»... y yo... veía... que escenas y eso me estaban pasando que era... era... como que estaba tratando de... de volverme loca ¿eh? Entonces, por eso de analizarlo y he dado veinte mil vueltas al... al asunto y he comprendido... un montón de cosas... a base de... de pensar en ello... (GD2)

La mujer queda cautiva en un proceso de confusión donde la autoinculpación aparece como resultado de un proceso de distorsión de la realidad.

\section{CONCLUSIONES}

Las explicaciones sobre las causas de los malos tratos conyugales han sido abordadas desde rasgos psicológicos de ambos géneros, estudios de socialización, modelos explicativos psicoanalíticos, sistémicos y cognitivos, sociológicos como las aportaciones feministas y modelos explicativos biológicos y evolutivos (30). No obstante, para Rhodes y Baranoff McKenzie (1), citados al inicio: «Ninguna teoría de forma única es capaz de aportar el grado de comprensión que buscamos».

Entre los modelos propuestos en la revisión teórica, sólo la formulación de «ciclo de la violencia», y el concepto de «persuasión coercitiva», permitieron una aplicación comprensiva de todos los códigos y categorías que fueron emergiendo en el análisis cualitativo. Mantenemos abierta la consideración sobre si el «ciclo de la violencia» debiera incluirse en el segundo concepto.

El desarrollo teórico fue inductivo. Progresivamente las conductas del maltratador y los efectos sobre las víctimas nos fueron mostrando que se trataban de estrategias dentro de un proceso de coerción. Para valorar la validez de este modelo aplicamos a dichos datos dos clasificaciones de estrategias de persuasión coercitiva: el esquema de coerción de Biderman (64) ya utilizado por algunos autores $(15,54)$ y la clasificación de Rodríguez Carballeira (17) (Tablas 1 y 2). Para nuestro propósito, no consideramos en esta última aquellas técnicas que se trataban claramente de mecanismos específicos en su empleo por sectas (ej. manipulación de las emociones para generar un sentimiento de pertenencia al grupo). 
Tabla 1

Esquema de coerción de Biderman* (64)

\begin{tabular}{|l|l|}
\hline \multicolumn{1}{|c|}{ MÉTODOS GENERALES } & \multicolumn{1}{c|}{ EFECTOS (PROPÓSITOS) } \\
\hline Aislamiento & $\begin{array}{l}\text { Privar a la víctima de todos los soportes sociales debilitando } \\
\text { su habilidad para resistir } \\
\text { Generar en ella un intenso interés por él } \\
\text { Hacer a la víctima dependiente del interrogador }\end{array}$ \\
\hline $\begin{array}{l}\text { Monopolización de } \\
\text { la percepción }\end{array}$ & $\begin{array}{l}\text { Fijar la atención sobre situaciones inmediatas; promover la } \\
\text { introspección } \\
\text { Eliminar estímulos que compitan con los controlados por el } \\
\text { captor } \\
\text { Frustrar todas las acciones que no estén de acuerdo con la } \\
\text { sumisión }\end{array}$ \\
\hline Debilidad inducida; agotamiento & Debilitar la habilidad física y mental para resistir \\
\hline Amenazas & Cultivar la ansiedad y la desesperación \\
\hline Indulgencias ocasionales & $\begin{array}{l}\text { Proveer motivaciones positivas para la sumisión } \\
\text { Impedir adaptaciones a la privación }\end{array}$ \\
\hline Demostración de «omnipotencia» & Sugerir la futilidad de la resistencia \\
\hline Degradación & $\begin{array}{l}\text { Hacer que el precio de la resistencia parezca más dañino a la } \\
\text { autoestima que la capitulación } \\
\text { Reducir al prisionero a preocupaciones a un «nivel animal» }\end{array}$ \\
\hline Imponer demandas triviales & Desarrollar hábitos de sumisión \\
\hline
\end{tabular}

* Amnesty Internacional (1975) report on torture

Tabla 2

Técnicas coercitivas de la clasificación de Rodríguez Carballeira (17) aplicables a la violencia de género.

\begin{tabular}{|l|l|}
\hline 1. Técnicas de tipo ambiental: & $\begin{array}{l}\text {. aislamiento o separación de la red de soporte social } \\
\text {. control de la información } \\
\text {. creación de un estado de dependencia existencial } \\
\text {. debilitamiento psicofísico. }\end{array}$ \\
\hline 2. Técnicas de tipo emocional: & $\begin{array}{l}\text {. activación emocional del miedo, la culpa y la ansiedad con } \\
\text { la aplicación selectiva de premios y castigos } \\
\text {. denigración del pensamiento crítico. }\end{array}$ \\
\hline
\end{tabular}


Tras aplicar ambos esquemas a nuestros datos, encontramos numerosos fragmentos a los que se podía asignar alguna de las estrategias enumeradas. Ningún fragmento de las transcripciones contradecía cualquiera de dichas estrategias. Esto nos daba un mayor apoyo para continuar analizando los datos bajo los presupuestos de la existencia de un modelo de persuasión coercitiva en la violencia de género.

En el momento de la investigación, no habíamos hallado todavía pese a la búsqueda intensiva durante el estudio, la referencia del artículo de Boulette y Andersen de 1985, por lo cual no pudimos aplicarlo. Consideramos dicho artículo esencial. De hecho nuestro trabajo confirma y apoya desarrollos ya planteados en el mismo.

Si bien en investigación cualitativa se prefiere hablar de «informe» reservando el concepto de «conclusiones» a investigaciones de carácter cuantitativo, presentamos a modo de estas últimas las consideraciones que consideramos más relevantes de nuestra investigación.

1. El mantenimiento o prolongación de la mujer en una relación de violencia de género puede ser comprendida entendiendo esta violencia como una forma de persuasión coercitiva.

2. Las distintas formas de violencia buscan el control constante de la víctima por parte del maltratador, cuya relación, bajo sus términos, él necesita. El aislamiento junto al control en el tiempo del ejercicio de los actos violentos modulan el proceso.

3. Al igual que en los movimientos sectarios organizados que practican la coerción se añade alguna estrategia específica para conseguir su fin (como generar un sentimiento de felicidad por la pertenencia y reconocimiento por el resto del grupo y especialmente del líder), la violencia de género tiene también técnicas particulares adaptativas para mantener su fin (éste es el caso de la técnica de arrepentimiento del ciclo de la violencia).

4. El modelo de persuasión coercitiva, no pretende dar cuenta de las motivaciones profundas individuales del maltratador, ni del contexto cultural o social que lo promueve o silencia. Expresado de otra forma, la violencia de género utiliza la persuasión coercitiva como único medio posible para conseguir que la víctima permanezca en la relación, pero la violencia de género es en sí un fenómeno aún mucho más complejo.

5. Comparado con otros modelos propuestos: aplicación del concepto de masoquismo, el modelo de indefensión aprendida o el trastorno por estrés postraumático, el modelo de persuasión coercitiva presenta una ventaja fundamental: permite integrar estrategias que actúan a distintos niveles (cognitivo, emocional y, social) sobre las víctimas.

6. La aplicación de este modelo, conserva algunas similitudes con la del «síndrome de Estocolmo» adaptado a la violencia de género, en el sentido de que no describe a la mujer como un agente meramente pasivo sin capacidad de respuesta ante la violencia. 
7. Uno de los hallazgos que consideramos fundamentales en nuestra investigación y ha sido escasamente desarrollado en otros modelos, es el papel que juegan las emociones como elementos que favorecen el mantenimiento del maltrato. Así, la emoción del miedo iría dirigida a generar paralización en la víctima; la culpa impuesta por la propia persuasión vincularía a la víctima al maltratador por su función reparadora, mientras que la vergüenza favorecería el retraimiento social de la víctima y la ocultación de su situación, completando con ello el aislamiento social. El estudio de estas y otras emociones es crucial para comprender el alcance y la efectividad de la persuasión coercitiva y serán abordadas en un segundo artículo que completa a esta primera parte.

\section{BIBLIOGRAFÍA}

1. Rhodes, N.; Baranoff McKenzie, E., «Why do battered women stay? Three decades of research», Aggresion and Violent Behavior, 1998, 3, 4, pp. 391-406

2. Snell, J.E.; Rosenwald, R.J.; Robey, A., «The wife-beater's wife: A study of family interaction». Arch Gen Psychiatry, 1964, 11, pp. 107-113

3. Orengo, F., «Sobre la cuestión de la compulsión a la repetición en la psicoterapia grupal de mujeres afectadas por violencia doméstica o de género». Psiquis, 2002, 23, 5, pp. 178-184

4. Bleichmar, H., Avances en psicoterapia psicoanalítica, Barcelona, Paidós, 1997.

5. Hirigoyen, M.F., El acoso moral. El maltrato psicológico en la vida cotidiana, Barcelona, Paidós, 1999.

6. Walker, L.E., The battered women. New York, Harper and Row; 1979.

7. Seligman, MEP., Indefensión. Debate. Madrid; 1981

8. LaViolette, A.; Barnett 0., It could happen to anyone. Why battered women stay, 2nd ed., Thousand Oaks, California, Sage Publications, 2000.

9. Gelles, R.J.; Straus, M., «Determinants of violence in the family», en: Burr, WR.; Hill, R.; Nye, F.I.; Reiss, I.L., Ed: Contemporary Theories about the Family, New York, Free Press, York, 1979.

10. ONU, Informe de la ONU, $n^{\circ}$ ST/CSDHA/2, 1989.

11. Graham, D.L.; Rawling, E.L., «Bonding with abusive dating partners: dynamics of Stockholm syndrome», en: Levy, B. (ed), Dating Violence, Women in Danger, Seattle, WA, Seal Press, 1991.

12. Ferreira, G.; Hombres violentos, mujeres maltratadas, $2^{\mathrm{a}}$ ed., Buenos Aires, Ed. Sudamericana, 1995.

13. Montero, A., «Shaping the etiology of the Stockholm Syndrome: hypothesis of the Induced Mental Model». IberPsicología, 1999, 5, 1.

14. Montero, A., «Síndrome de adaptación paradójica a la violencia doméstica: una propuesta teórica», Clínica y Salud, 2001, 12, 1, pp. 5-31 
15. Miller, M.S., No visible wouds, New York, Fawcett Books, 1995.

16. Boulette,T.S., Andersen, S.M., «Mind control and the battering of women», Community Ment Health J., 1985, 21, 2, pp. 109-18. También en: Cultic Studies Journal, 1986, 3, 1.

17. Rodríguez Carballeira, A. El lavado de cerebro. Psicología de la persuasión coercitiva, Barcelona, Editorial Boixareu Universitaria, 1992.

18. Loewenstein, R.J.; Putnam, F.W., «Dissociative Disorders», en: Sadock, B.J.; Sadock, V.A., Kaplan \& Sadock's Comprehensive Textbook of Psychiatry, 8th ed, Philadelphia, Lippincott Williams \& Wilkin, 2005.

19. Singer, M.T., Lalich, J., Las sectas entre nosotros, $2^{\mathrm{a}}$ ed., Barcelona, Gedisa, 2003.

20. American Psychiatric Association, Diagnostic and Statistical Manual of Mental Disorders, 4th ed., Text rev. Washington, DC, American Psychiatric Association, 2000 .

21. Sadock, V.A., «Other additional conditions that may be a focus of clinical attention», en: Kaplan, H.I., Sadock, B.J. (editors). Comprehensive Textbook of Psychiatry/VI, 6th ed., Baltimore, Maryland, Williams \& Wilkins, 1995.

22. Escudero, A., Factores que influyen en la prolongación de una situación de maltrato a la mujer: un análisis cualitativo, [Tesis Doctoral], Departamento de Psiquiatría, Universidad Autónoma de Madrid, 2004.

23. Glaser, B.G.; Strauss, A.L., The discovery of grounded theory, Chicago, Aldine, 1967.

24. Mays, N.; Pope, C., «Qualitative research: rigour and qualitative research», BMJ, 1995, 311, pp. 109-112.

25. Ibáñez, J., Más allá de la sociología. El grupo de discusión: Técnica y Crítica, $4^{\mathrm{a}}$ ed., Madrid, Siglo XXI de España Editores, 2000.

26. Ibáñez, J., Las ciencias sociales en España: historia inmediata, crítica y perspectiva, Madrid, Universidad Complutense, 1992.

27. Canales, M.; Peinado, A., «Grupos de Discusión», en: Delgado, J.M.; Gutierrez, J. (Cor.), Métodos y técnicas cualitativas de investigación en ciencias sociales, Madrid, Editorial Síntesis, 1994.

28. Valles, M.S., Técnicas cualitativas de investigación social, Madrid, Editorial Síntesis, 1997.

29. Callejo, J., El grupo de discusión: introducción a una práctica de investigación, Barcelona, Ariel, 2001.

30. Polo, C., Maltrato a la mujer en relación de pareja. Factores relacionales implicados, [Tesis Doctoral], Departamento de Especialidades Médicas, Universidad de Alcalá, 2001.

31. Straus, M.A., «Measuring intrafamily conflict and violence: The conflict tactics scales», J Marriage Fam, 1979, 41, pp.75-88. 
32. Shepard, M., Campbell, J. «The Abusive Behavior Inventory: a measure of psychological and physical abuse», Journal of Interpersonal Violence, 1992, 7, 3, pp. 291-305.

33. Pandit, N.R., «The creation of theory: a recent application of the Grounded Theory method», The Qualitative Report, 1996, 2, 4.

34. Muhr T. ATLAS.ti. Visual qualitative data análisis management model building. Versión Win 4.2. Berlin: Scientific Software Development; 2004.

35. Miles, M., Huberman, M., Qualitative Data Analysis. $2^{\mathrm{a}}$ Ed., London, SAGE Publications, 1994.

36. Charmaz, K.; Mitchel, R.G., «Grounded Theory and Ethnography», en: Atkinson, P.; Coffey, A.; Delamont, S.; Lofland, J.; Lofland, L., eds: Handbook of Etnography, London, Sage, 2001.

37. Monzón, I. «La violencia doméstica desde una perspectiva ecológica», en: Corsi, J., Maltrato y abuso en el ámbito doméstico, Buenos Aires, Paidós, 2003.

38. Real Academia Española, Diccionario de la Lengua Española, 22 ${ }^{\mathrm{a}}$ ed., Madrid, Espasa Calpe, 2001.

39. Lorente, M., El rompecabezas. Anatomía del maltratador, Barcelona, Ares y Mares, 2004.

40. Dutton, D.G.; Golant, S.K., El golpeador. Un perfil psicológico, Buenos Aires, Paidós, 1997.

41. Mahler, M.; Pine, F.; Bergman, A., El nacimiento psicológico del infante humano, Buenos Aires, Marymar Ediciones, 1977.

42. Mahler, M., Estudios 2. Separación-individuación, Buenos Aires, Paidós, 1984.

43. Jukes, A.E., Men who batter women, Londres-Nueva York, Routledge, 1999.

44. Balint, M. The basic fault. London, Tavistock, 1967.

45. Faulk, M., «Men who assalult their wives», Medicine Science and the Law, 1974, 14, pp. 180-183.

46. Saunders, D.G., «A tipology of men who batter: three types derived from cluster analysis», Am J Orthopsychiatry,1992, 62, 2, pp. 264-275.

47. Jacobson, N.; Gottman, J., Hombres que agreden a sus mujeres. Cómo poner fin a las relaciones abusivas, Barcelona, Paidós, 2001.

48. Straus, M.A.; Gelles, R.J.; Steinmetz, S.K., Behind closed doors: Violence in the American Family. Garden City, New York, Anchor Press/Doubleday, 1980.

49. Larrain, S., Violencia puertas adentro. La mujer golpeada, Santiago de Chile, Editorial Universitaria, 1994.

50. Campbell, J.C., «Abuse during pregnancy: A quintessential threat to maternal and child health -- so when do we start to act? ", Can Med Assoc J, 2001, 164, 11, pp. 1578-1580.

51. Entel, R., Mujeres en situación de violencia familiar, Buenos Aires, Espacio Editorial, 2002. 
52. Castro, R.; Peek-Asa, C.; Ruíz, A., «Violence against women in Mexico: A study of abuse before and during pregnancy», Am J Public Health, 2003, 93, 7, pp. 1110-1116

53. García de Keltai, I., «Discusión acerca de los determinantes de la agresividad y la violencia», en: Corsi, J. (ed), Maltrato y abuso en el ámbito doméstico, Buenos Aires, Paidós, 2003.

54. Russell, D.E.H., Rape in Marriage (Expanded and revised edition; originally published in 1982), Bloomimgton and Indianapolis, Indiana University Press, 1990.

55. Finkelhor, D.; Yllo, K., License to rape. Sexual abuse of wives, New York, Holt, Rinehart and Winston, 1985.

56. Follingstad, D. y otros., "The role of emotional abuse in phisical abusive relationships», Journal of Family Violence, 1990, 5, 2, pp. 107-120.

57. Sluzki, C., «Violencia familiar y violencia política», en: Fried Schnitman, D. (compilador), Nuevos paradigmas, cultura y subjetividad, Buenos Aires, Paidós, 1994.

58. Peterson, Ch.; Maier, S.F.; Seligman, M.E.P., Learned helplessness. A theory fot the age of personal control, New York, Oxford University Press, 1993.

59. Walker, L.E., «The battered Woman Syndrome Study», en: Finkelhor, D.; Gelles, R.J.; Hotaling, G.T.; Straus, M. (ed), The Dark Side of families, California, Sage Publications, 1983.

60. Walker, L.E., Battered woman syndrome, New York, Ed. Springer, 1984.

61. Walker, L.E., «El perfil de la mujer víctima de la violencia», en: Sanmartín, J., (ed), El laberinto de la violencia. Causas, tipos y efectos, Barcelona, Ariel, 2004.

62. Bancroft, L., Why does he do that? Inside the minds of angry and controlling men, New York, Berkeley Books, 2003.

63. Iturralde, C., Familia y pareja: comunicación, conflicto y violencia, en: Corsi, J., (ed), Maltrato y abuso en el ámbito doméstico, Buenos Aires, Paidós, 2003.

64. Amnesty Internacional, Report on torture, London: Gerald Duckworth \& Co. 1975.

Antonio Escudero Nafs

Psiquiatra

Servicios de Salud Mental de Majadahonda (Madrid). SERMAS

Cristina Polo Usaola

Psiquiatra, jefa de Distrito

Servicios de Salud Mental de Hortaleza (Madrid). SERMAS

Marisa López Gironés

Psicóloga clínica

Servicios de Salud Mental de Hortaleza (Madrid). SERMAS 
Lola Aguilar Redo

Pediatra

SESCAM (Guadalajara)

Correspondencia:

Antonio Escudero Nafs

Psiquiatra

Servicios de Salud Mental de Majadahonda (Madrid)

SERMAS

Avda de España, $n^{0} 7,28220$, Majadahonda, Madrid anescuderonafs@telefonica.net 